\title{
PERDURACIÓN SIMBÓLICA EN EL USO DE UNA NECRÓPOLIS IBÉRICA. EL EDIFICIO FUNERARIO DE CERRO DEL SANTUARIO (BAZA, GRANADA)
}

\author{
SYMBOLIC PERDURANCE IN THE USE OF AN IBERIAN NECROPOLIS. THE FUNERARY BUILDING \\ IN CERRO DEL SANTUARIO (BAZA, GRANADA)
}

\author{
ALEJANDRO CABALLERO COBOS \\ Centro de Estudios de Arqueología Bastetana \\ JUAN A. SALVADOR OYONATE \\ Centro de Estudios de Arqueología Bastetana
}

ANDRÉS MARÍA ADROHER AUROUX

Universidad de Granada

\section{INTRODUCCIÓN}

El Cerro del Santuario es un yacimiento ampliamente conocido como necrópolis ibérica, entre otros motivos por ser el lugar donde se halló la estatua de la Dama de Baza.

No obstante, una necrópolis ibérica puede presentar una complejidad estructural muy superior a lo que suelen dejar entrever la mayor parte de las publicaciones que se realizan sobre ellas. Y no sólo porque no conozcamos correctamente su articulación interna (caminos, cercas, y otros tipos de elementos arquitectónicos más o menos iconográficos que debieron estar presentes en el paisaje y lo que se ha dado en llamar el skyline de las necrópolis), sino porque muchas de ellas albergan variados y complejos sistemas de continuidad en el uso del espacio, aunque éste haya variado más o menos esencialmente, pero en el cual no resulta difícil apreciar cierta continuidad de carácter simbólico.

Y en nuestro caso, ya las excavaciones realizadas por F. Presedo entre 1968 y 1971 detectaron y dejaron visibles una gran cantidad de estructuras que van más allá de las simples (o complejas) tumbas, y que, además, incluyen algunas muy posteriores en el tiempo (Presedo, 1982).

Nos centraremos en este estudio en un edificio que ya el excavador lo relacionó con ambientes funerarios, sin mayor precisión. Se trata de un recinto con forma de U orientado hacia el Este, al que se adosa otro recinto en forma también de U por el Oeste de dimensiones algo menores y que da forma a una pequeña estancia. El carácter funerario viene definido por la documentación de una tumba de inhumación doble en el interior del primer recinto, así como de otro enterramiento más, situado al exterior del mismo, junto al muro meridional. Entre ambos apenas aparecieron algunos fragmentos de vidrio que permitió proponer una cronología romana, concretamente imperial, según sus propias palabras $^{1}$.

Recientemente, en el año 2013, durante las labores de limpieza y documentación con el objetivo de rehabilitar parte del yacimiento, hemos aprovechado para tomar nuevos datos que pudieran ayudarnos a comprender mejor esta extraña estructura de la que se conservan menos elementos que los que en su día se definieron en la publicación (Presedo, 1982, 258-262). No obstante, en dicha monografía, se mencionaba que este edificio ya era parcialmente visible antes del comienzo de la excavación (Fig. 1), describiéndolo como un espacio definido por dos estancias, con muros de mampostería ligados con argamasa de cal y dentro de los cuales persistían numerosos muros de adobes o de pequeños mampuestos, muchos de los cuales, por cierto, están hoy completamente desaparecidos.

\section{DESCRIPCIÓN ARQUITECTÓNICA}

Los nuevos trabajos arqueológicos y de documentación de los restos de este edificio nos han permitido obtener una planimetría detallada del mismo, que pudimos contrastar con la publicada anteriormente (Fig. 2).

La construcción, orientada a $281^{\circ} \mathrm{N}$, presenta un complejo estructural compuesto por dos recintos. La

1. «...Son de indudable factura romana, por cuya razón atribuimos el monumento a esta época y nos inclinamos a situarlo, con todas las reservas, en época imperial» (Presedo, 1982, 262) 


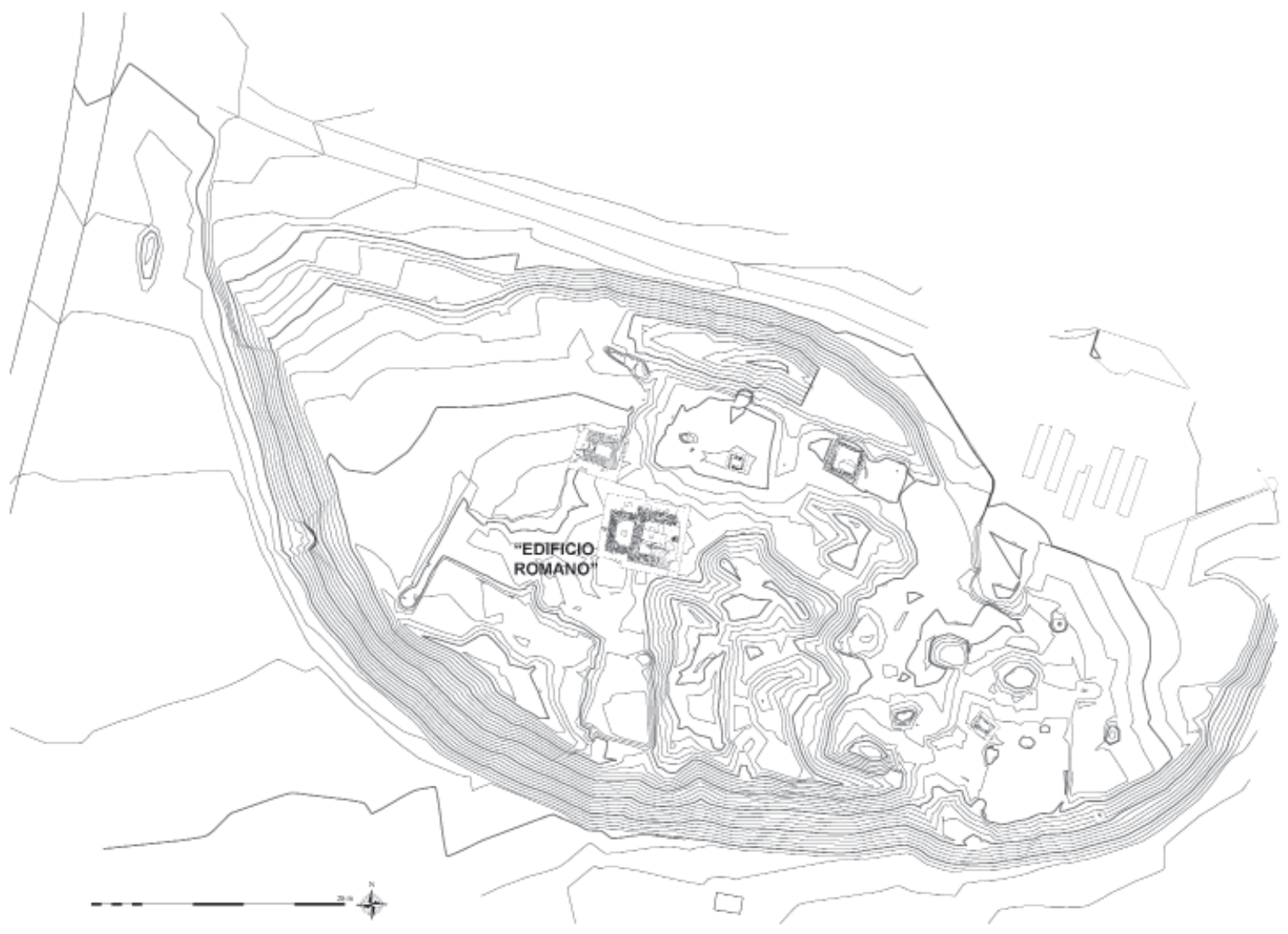

Figura 1: Localización del edificio romano en el cerro del Santuario de Baza (Granada) (elaboración propia).

estancia más oriental está delimitada por unos muros cuyo grosor oscila entre los 90 y $100 \mathrm{~cm}$, mientras que la más pequeña, adosada a la pared occidental de la anterior, son menores $(80 \mathrm{~cm})$. Ambas tienen una

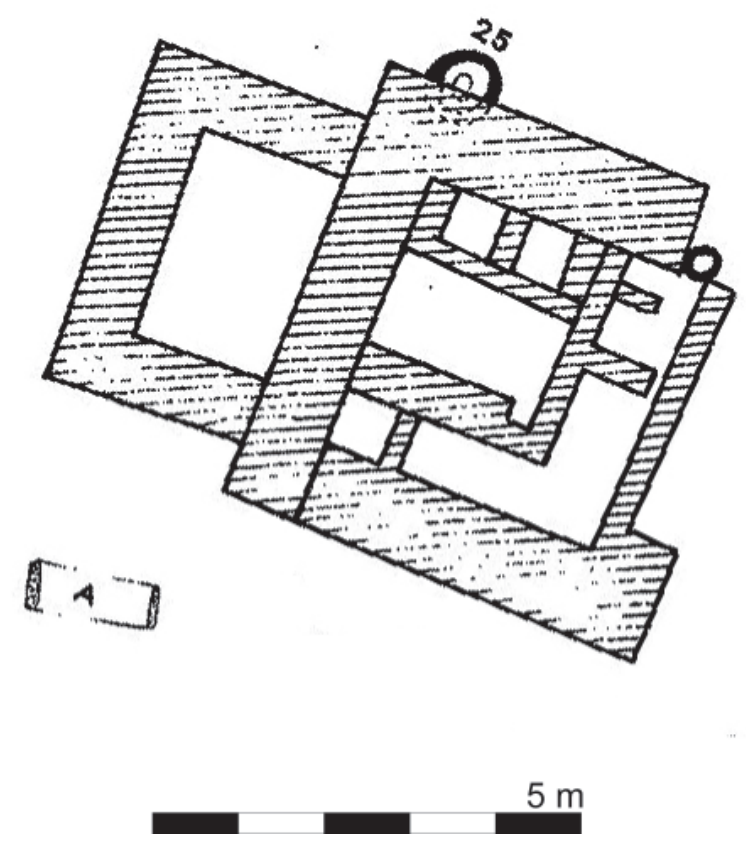

Figura 2: Planimetría del «edificio romano» según F. Presedo (1982, fig. 6). técnica constructiva idéntica: mampuestos de pequeño y mediano tamaño ligados con una argamasa de cal de color marrón, lo cual descartaba la idea que nos encontrásemos ante dos fases cronológicas diferentes, sino más bien ante distintas fases constructivas dentro de un planteamiento arquitectónico único. En las caras exteriores de dichos muros se aprecia una disposición de los mampuestos en pseudohiladas, lo que unido a la ausencia de revocos o revestimientos nos sugiere que sólo conservamos las cimentaciones del edificio, hecho que se apoya también en la ausencia de vanos perceptibles en dichos muros.

La naturaleza de los mampuestos es relativamente variada; por un lado materiales metamórficos, generalmente cantos de rio, básicamente esquistos y cuarcitas; por otra parte contamos con diversas rocas sedimentarias, entre las que destacamos calizas micríticas, travertinos y una roca tabular sedimentaria muy característica de la zona conocida como jabaluna. Todo ello nos permite concluir que el material viene reutilizado de edificaciones anteriores, tanto de la propia necrópolis (donde la jabaluna es, junto al adobe, el material constructivo más frecuente), como del hábitat (Cerro Cepero, situado a unos 600 metros al Este), de donde podrían proceder los cantos de río utilizados en los niveles constructivos ibéricos, especialmente de época antigua y plena, las calizas micríticas utilizadas en la construcción de la muralla (ibérica) o del templo 


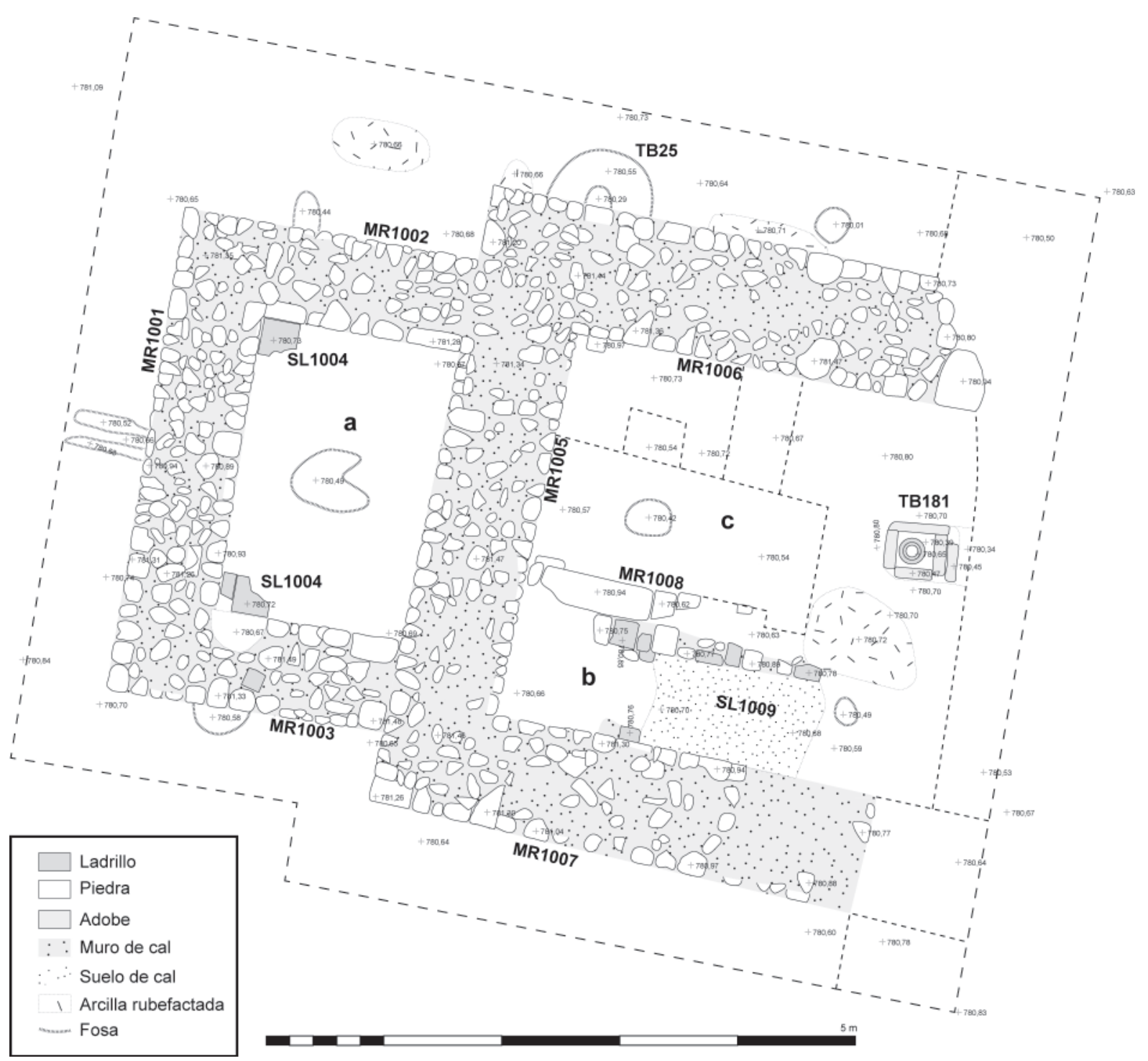

Figura 3: Planimetría del «edificio romano» tras la limpieza de estructuras de 2013 (elaboración propia).

(altoimperial), los travertinos localizados en muchas de las estructuras desde las primeras fases republicanas, o incluso, una vez más, las jabalunas, detectadas en muros tardoibéricos y también altoimperiales. Una prueba más de la reutilización de los mampuestos es que algunos de ellos son restos de sillerías fracturadas, especialmente visible en el caso de los travertinos.

Por otra parte, el tamaño medio de los mampuestos no suele superar los $30 \mathrm{~cm}$, salvo algún caso aislado, lo que provoca que desde ciertas perspectivas parezca tratarse de opus caementicium como los localizados en otros monumentos funerarios romanos (Jiménez Salvador, 1992, 544; Ruiz-Alcalde y Charquero, 2014, 156), pero el tamaño de los clastos, así como la ausencia de cajas de fraguado, impide considerar otra técnica constructiva que no sea un opus incertum donde se ha utilizado una cantidad de argamasa algo superior a lo que nos tienen acostumbrados otros muros en el conjunto arqueológico (Fig. 7).

Pasando a la descripción de las estancias, la occidental presenta una planta rectangular $(2,50 \times 1,65$ $\mathrm{m})$, con una superficie aproximada de $4 \mathrm{~m}^{2}$. En las esquinas $\mathrm{SO}$ y NO han aparecido restos de una solería de baldosas cuadradas $(31 \times 31 \mathrm{~cm})$ de cerámica, que se sitúan a un nivel $70 \mathrm{~cm}$ inferior a la cota de arrasamiento de los muros de la habitación, de lo que inferimos que esta habitación tenía carácter semi-subterráneo (Fig. 3).

La habitación oriental es de dimensiones algo mayores $(3,30 \times 3,40 \mathrm{~m})$ contando con algo más de 11 $\mathrm{m}^{2}$, encontrándose abierta por su lado Este, lo cual nos lleva a establecer la hipótesis de que nos encontramos ante un posible pórtico o un área abierta con bancos corridos en sus laterales. Tres argumentos se pueden esgrimir para afirmar que no existió un muro que cerrara el perímetro por la parte oriental. En primer lugar, a pesar de que nos encontramos con la infraestructura del edificio, es decir, con la fundación, no se conservaba, ni siquiera cuando Presedo lo terminó de desenterrar, ni una sola piedra que indicara que dicho muro hubiese sido alterado, desmontado o simplemente expoliado; en segundo lugar, a pesar de que no hay 


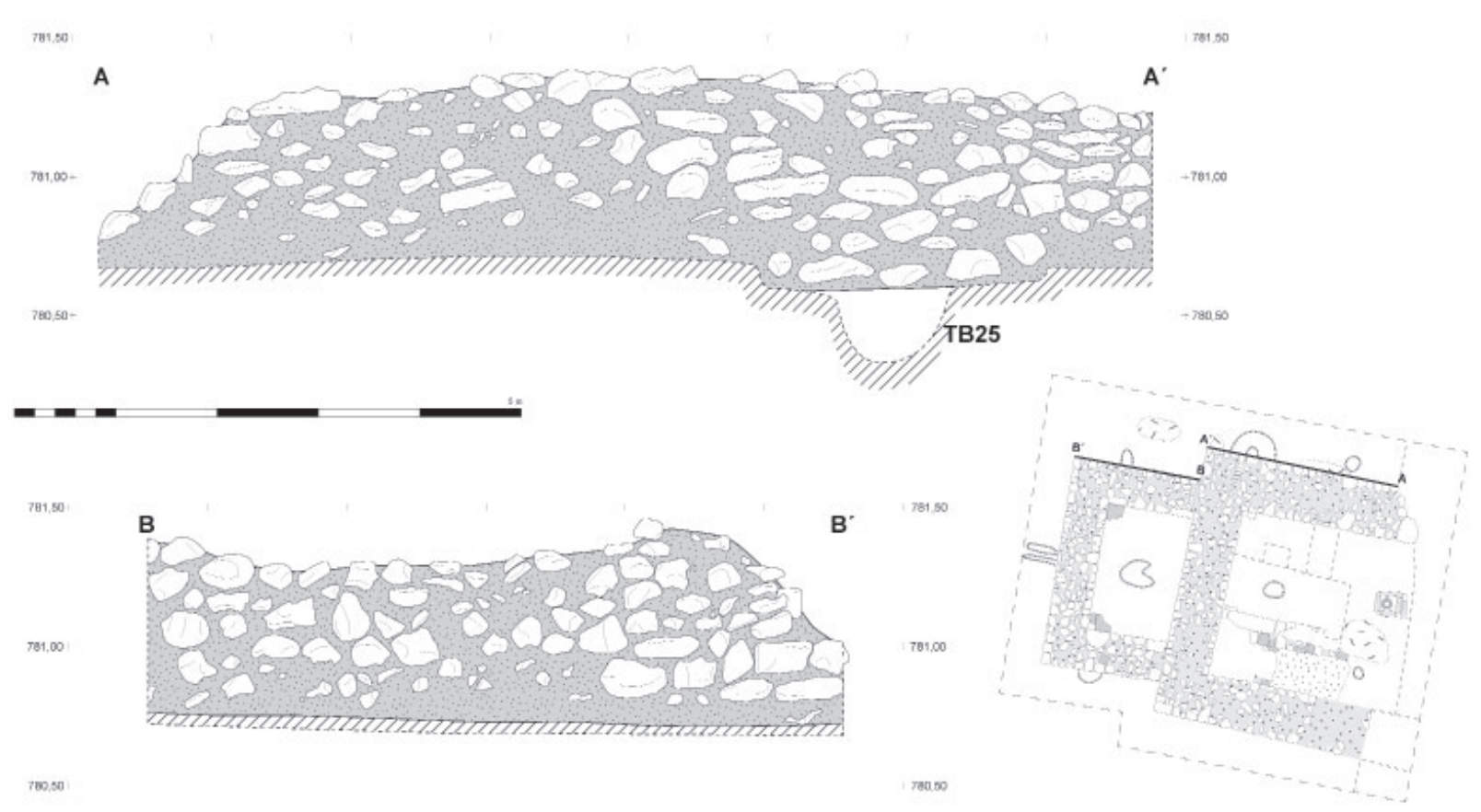

Figura 4: Planimetría del edificio y alzado de los muros de la cara noreste (elaboración propia).

apenas cambios en la horizontalidad del terreno donde se sitúa el muro, y de que aún hemos podido profundizar un poco más en su entorno, no se ha identificado restos de la fosa de fundación de dicho muro; en tercer lugar, existe un mampuesto de travertino (Fig. 8), restos de un sillar amortizado y roto - quizás el más grande de los utilizados en la construcción del edificio-que se sitúa en el extremo oriental del muro septentrional no tratándose de un refuerzo de esquina, pues esa técnica es del todo ajena en el resto de la construcción por lo que habría que considerar que existe un cambio importante en el sistema constructivo en este extremo

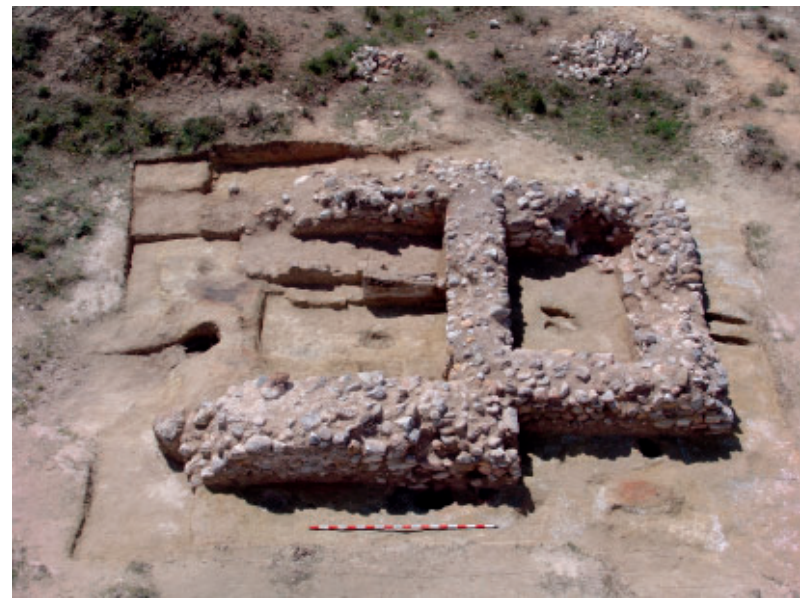

Figura 5: Vista desde el lado norte del edificio romano. En el centro de la imagen, haciendo las veces de muro de separación, se puede ver uno de los elementos arquitectónicos decorados originales, que fue reutilizado con posterioridad; a la izquierda, a modo de fosa circular, la tumba ibérica mencionada (fotografía: autores). de la edificación, que, insistimos, debió estar abierta o, como máximo, cerrada con un tabique; pero en ambas opciones impiden que ese muro oriental sirviese de soporte de una estructura de cubierta más o menos pesada, por lo que estaríamos hablando de un espacio porticado.

En la planta dibujada por F. Presedo se aprecian múltiples estructuras en su interior (Fig. 2) de las cuales, sin embargo, sólo pudimos constatar un tabique de ladrillos y mampuestos ligados con cal en su tercio meridional con el que funcionaba un suelo del mismo compuesto de cal que se adosaba a la cimentación meridional de dicho pórtico o área abierta, formando un espacio rectangular de $1,50 \times 0,80 \mathrm{~m}$. La cal utilizada en este caso era de un color blanquecino, lo cual la distinguía claramente de la elaborada para la obra de los muros de cimentación, por lo que este receptáculo pertenece a una fase claramente posterior a la edificación primigenia.

Este espacio, además, puede asociarse con la inhumación doble revuelta localizada por F. Presedo $(1982,258)$. La otra inhumación documentada en esa excavación se situaba fuera del edificio, al suroeste del mismo, y aunque no fue referenciada en la publicación se puede identificar con la estructura rectangular marcada en la planimetría de F. Presedo con la letra A, (Fig. 2) puesto que las dimensiones descritas en el texto coinciden con aquella.

Las restantes estructuras dibujadas por F. Presedo en este espacio no han dejado resto alguno, por lo que dudamos de su existencia inicial. De hecho, las líneas de las estructuras dibujadas en su momento, hemos visto que pudieron corresponder con escalones rectilíneos excavados en el sustrato geológico, pudiéndose 
asociarse más al proceso de excavación que a la existencia de posibles tabiques ${ }^{2}$. Además, en el extremo nororiental del pórtico o espacio abierto, bajo uno de esos teóricos tabiques hallamos una tumba ibérica intacta $^{3}$ con su urna cineraria, que había sido ignorada en dicha excavación (Figs. 3 y 8).

\section{ELEMENTOS ARQUITECTÓNICOS}

A lo largo de diversas actuaciones realizadas en la necrópolis se han podido recuperar o documentar una serie de elementos arquitectónicos en piedra que, como intentaremos demostrar, podrían estar asociados a la construcción romana a la que nos hemos referido y que ayudarían a comprender su funcionalidad y su aspecto.

La primera pieza apareció reutilizada como mampuesto en el tabique de delimitación de la tumba doble de inhumación del lado Sur del pórtico o espacio abierto. Se trata de un bloque paralepípedo de 96x30x35 $\mathrm{cm}$. Una de sus caras presenta decoración longitudinal de tres acanaladuras de 3,5 cm de anchura; otra, colateral, aún conserva los restos de una sola acanaladura, aunque esta cara está muy alterada; la tercera es una cara fracturada, pero regular, y la cuarta es completamente lisa y presenta restos de tallado con maceta y con un peralte en uno de sus extremos. En el plano de su extremo superior presenta una muesca en forma de $\mathrm{Y}$, restos de la mortaja para una grapa de plomo que engarzaría con las piezas colindantes. Con estos datos, pensamos que se trata de una pieza esquinera destinada a simular una pilastra en su mitad inferior, a juzgar por el acabado en ángulo recto de las acanaladuras.

El tipo de piedra empleada para su tallado, caliza margosa, nos puso en la pista sobre otras dos piezas arquitectónicas conservadas en el Museo Arqueológico de $\mathrm{Baza}^{4}$ que procedían igualmente de Cerro Santuario y que fueron localizadas en superficie hacía tiempo, aunque después de las excavaciones de Presedo. Se trata de dos placas que encajan entre sí, formando una pieza de $120 \mathrm{~cm}$ de altura, con $48 \mathrm{~cm}$ de desarrollo a lo ancho y un grosor mínimo de $13 \mathrm{~cm}$. Consta de una decoración -que se concentra en la mitad superior- propia de una pilastra, con tres acanaladuras rematadas en semicírculo, acompañada a su izquierda de un friso de rombos en relieve sobre una moldura que se encuentra muy desgastada. En el lado derecho de la placa se aprecia la repetición del motivo de la pilastra,

2. Hay que pensar que la planimetría fue realizada por un técnico topógrafo que no había estado presente en la excavación, y que podría no conocer la naturaleza de los distintos rebajes que presentaba el terreno; esto también puede detectarte en otros errores que acumula la planimetría original de Presedo.

3. Esta es la que hemos denominado Tumba 181 que será publicada, en futuros trabajos, junto a otros nuevos hallazgos funerarios de época ibérica.

4. Donación de Guadalupe Llorente, vecina de la zona.

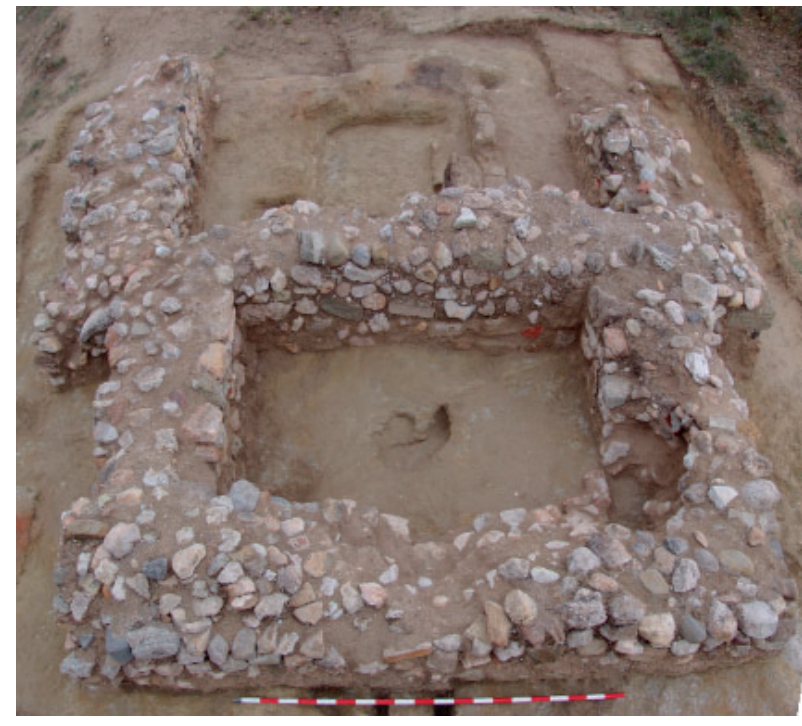

Figura 6: Panorámica desde el lado oeste del «edificio romano» (foto: autores)

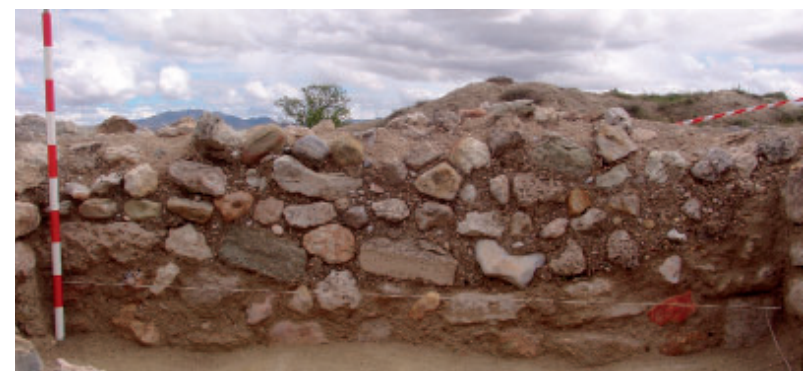

Figura 7: Detalle desde el Oeste del alzado oriental del MR1005 (foto: autores)

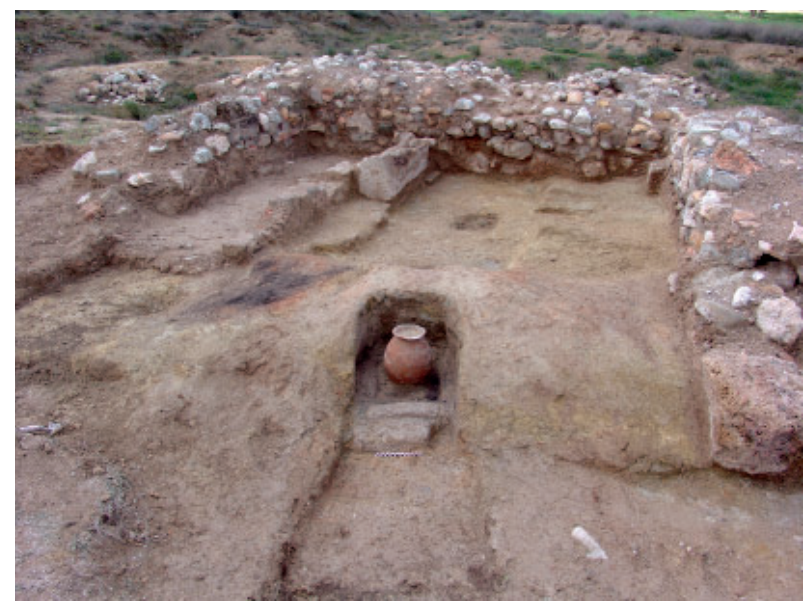

Figura 8: Vista desde el Este del edificio romano. A la derecha se puede observar el sillar que remata la obra del MR1006 y en el centro la TB181 (foto: autores)

con dos acanaladuras, lo que le confiere también una posición esquinera (Fig. 9).

Existe una tercera pieza arquitectónica encontrada en el yacimiento y exhumada por F. Presedo (1982, 167 y 322) en un contexto secundario, 8 metros al Norte de los cimientos del edificio, y que es definida 

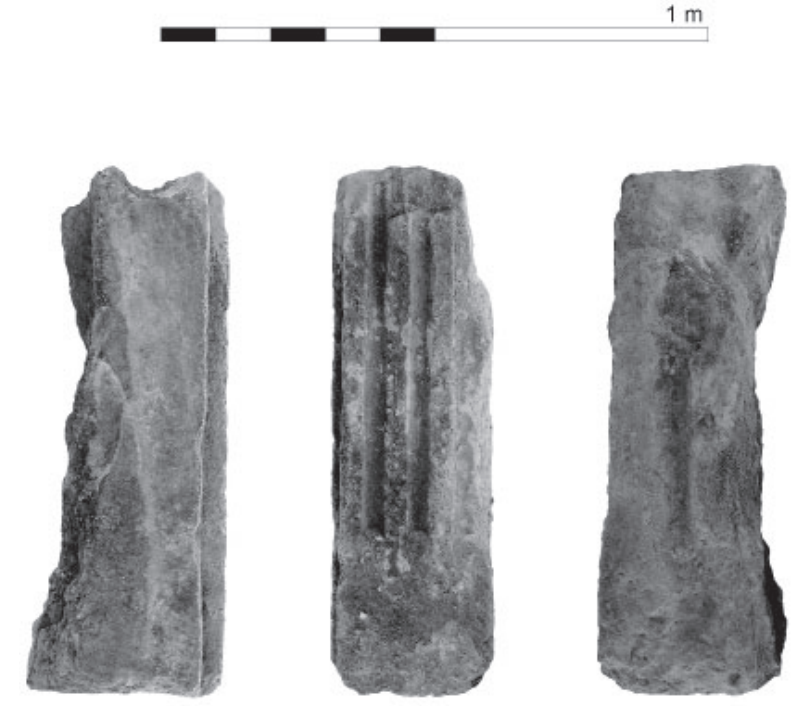

A
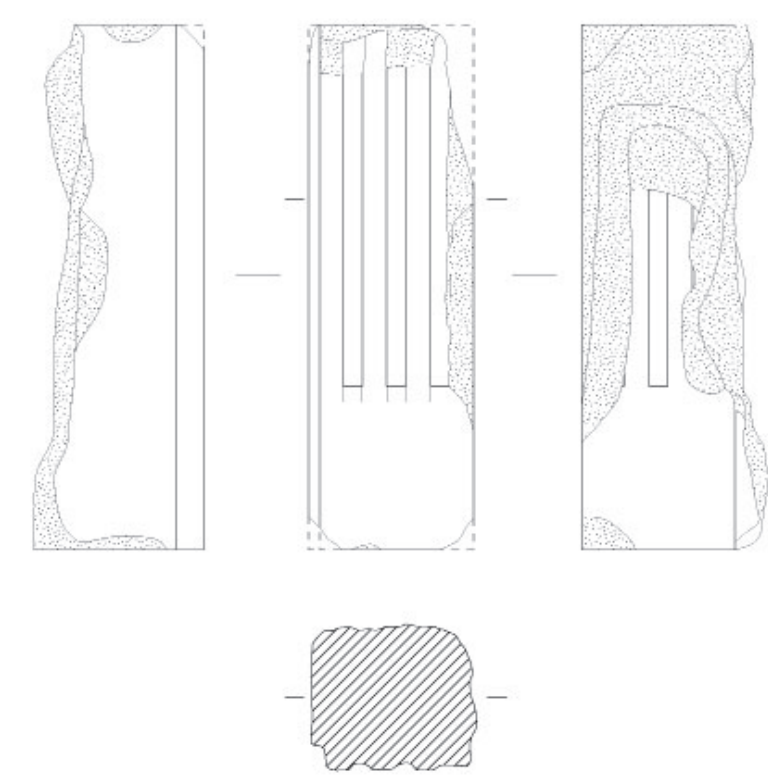

Figura 9: Elementos arquitectónicos decorados conservados en la actualidad en el Museo Arqueológico Municipal de Baza (MAB). El de la izquierda puede observarse la pieza esquinera reutilizada como muro medianero, mientras que la pieza fragmentada de la derecha sería parte de la decoración de la parte superior (elaboración propia).

en su obra escrita como «piedra caliza». Se trata de un fragmento esquinero de una cornisa de gola, de 1 metro de anchura y $30 \mathrm{~cm}$ de altura aproximadamente, del cual solo conocemos su forma por un par de fotos publicadas por Presedo ${ }^{5}$. Según se puede observar, esta pieza presenta una escocia pronunciada que une sendos toros, estando decorada la zona inferior por una acanaladura longitudinal. Además se señala que

5. El paradero actual de esta pieza nos es desconocido, lo que ha impedido verificar la presencia de marcas de grapa de plomo, y comparar la composición geológica de ésta con las otras piezas arquitectónicas conservadas.

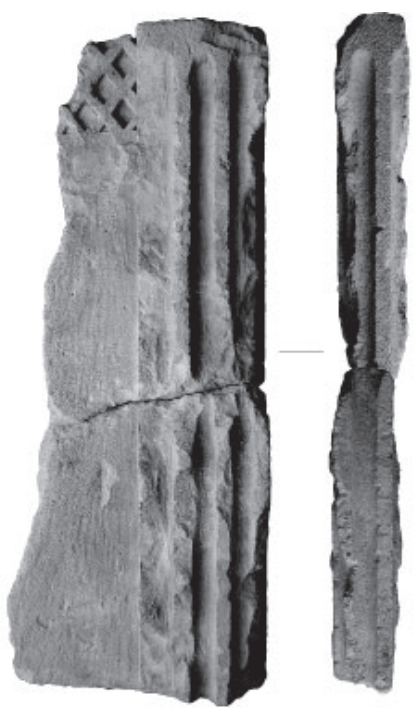

B
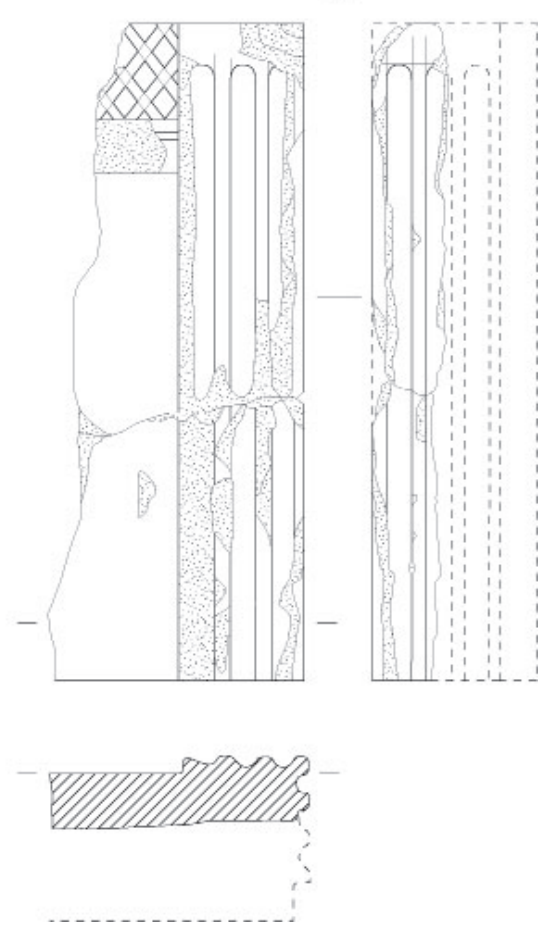

la superficie inferior, de menor tamaño, posee un rebaje para el encaje de otra pieza (Almagro, 1983, 257, n.501; Izquierdo, 2000, 93) (Fig. 10).

Es difícil asociar claramente todos estos elementos entre sí. De todas formas, optamos por ello ante una serie de evidencias que nos parecen fundamentales. Ante todo la seguridad de que todas estas piezas han sido localizadas en el mismo ámbito arqueológico, en la colina que forma el Cerro del Santuario, un pequeño promontorio de 5.200 metros cuadrados, lo cual permite asociarlas entre sí. Es igualmente importante resaltar la inexistencia de otras construcciones ulteriores a la necrópolis ibérica, al margen de nuestro edificio, lo que impediría considerar que se tratase de 


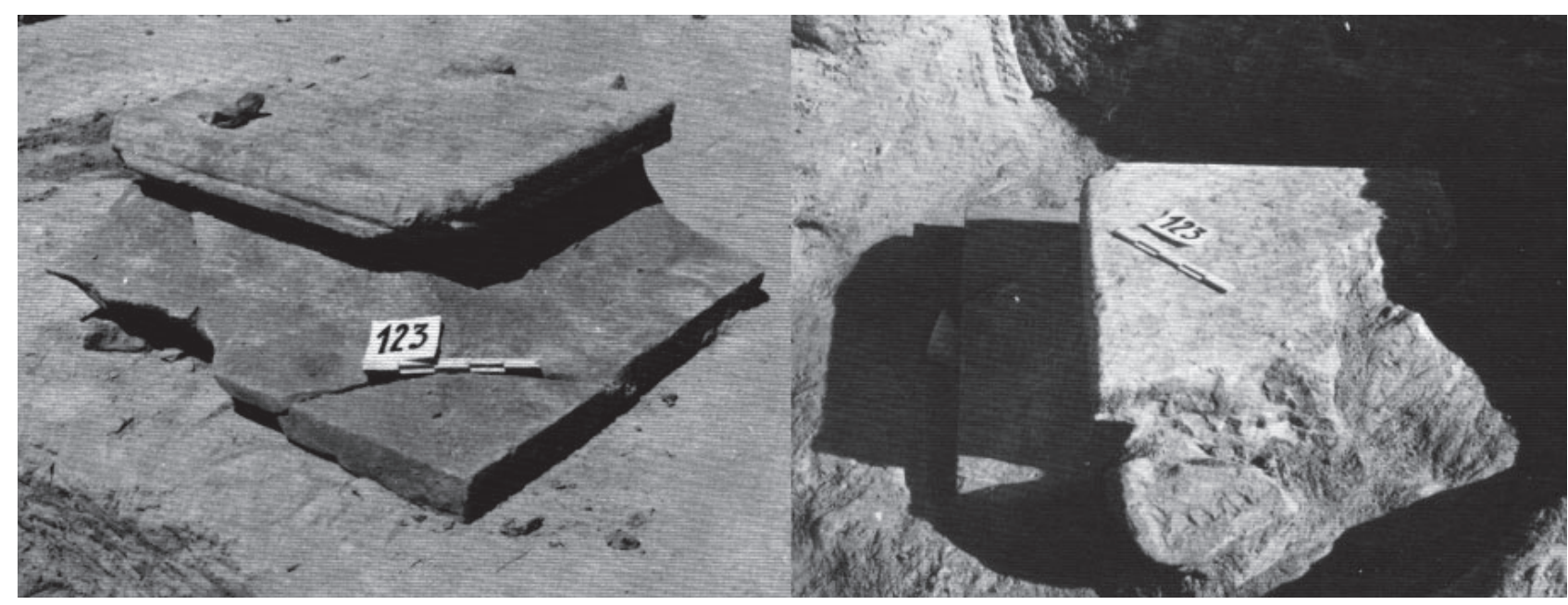

Figura 10: Elemento arquitectónico esquinero - gola egipcia- hallada por F. Presedo en su intervención arqueológica. En la actualidad sólo se conservan estas imágenes, desconociendo donde se encontraría este elemento arquitectónico en la actualidad (Presedo, 1982, lám. 35).

piezas reutilizadas traídas desde otros puntos con el fin de completar la necesidad de materiales de construcción. Por otra parte, todas estas piezas son elementos arquitectónicos de claro carácter decorativo, aspecto que lo pueden relacionar con un edifico monumental, y están constituidos por el mismo tipo de roca caliza, incluso en el caso de la gola encontrada por Presedo durante las excavaciones sobre el nivel de destrucción de la tumba ibérica 123 y en posición secundaria. El tipo de roca utilizado es un aspecto necesariamente a profundizar, ya que los pocos elementos constructivos en piedra que presentan las estructuras funerarias ibéricas están realizadas fundamentalmente en jabalunas, a excepción hecha de los elementos escultóricos localizados, como la famosa figura sedente conocida como Dama de Baza o algún elemento más identificado en nuestras últimas intervenciones, realizados sobre un soporte calizo pero de menor dureza que los que estamos presentando y, por tanto, de naturaleza distinta.

Un problema más serio podría venir de la mano del fragmento de cornisa. En primer lugar si fuese de factura ibérica ${ }^{6}$ sería el único elemento de decoración arquitectónico localizado en toda la necrópolis. Tampoco se han localizado sillares que permitan concebir una edificación más o menos compleja en la necrópolis. Por último, pero no por ello menos importante, los pilares estela no son propios del ámbito bastetano; de las necrópolis conocidas en nuestra zona no se contabiliza ni un solo elemento que permita considerar que durante los siglos V-IV a.C., momento álgido del uso de este tipo de monumentos funerarios, haya existido nada parecido en el paisaje de las necrópolis; y estamos hablando de conjuntos importantes como Tutugi

6. Considerándolo como restos de un monumento turriforme o pilar estela ibérico (Presedo, 1982, 322; Almagro, 1983, 257; Izquierdo, 2000, 93). Incluso en alguna ocasión nosotros mismos hemos defendido esa idea.
(Galera, Granada), Cerro Cepero (Baza, Granada), Iliberri (Albaicín, Granada), Ilurco (Pinos Puente, Granada), a excepción tal vez de lo que los leones de Trasmulas permitan considerar, aunque este monumento, no asociado por el momento a ningún asentamiento ni necrópolis conocida, parece retrotraerse al siglo VI a.C.

De modo que consideramos que estos argumentos anteriormente expuestos refuerzan la idea de que todos los elementos arquitectónicos que incluimos en este elenco debieron formar parte de un mismo programa constructivo, dada su homogeneidad. Y si consideramos que el único edifico romano con el que contamos en el yacimiento es el que aquí presentamos parece coherente considerar que el programa constructivo tuvo como base este monumento.

Tras esto, pasamos a continuación a contextualizar funcional y cronológicamente estas piezas a partir de los paralelos localizados. Lo más plausible es considerar que debieron pertenecer al revestimiento exterior del alzado del edificio cuyos cimientos conservamos en Cerro del Santuario, puesto que es la única construcción no ibérica de entidad en ese yacimiento. La cimentación conservada es bastante semejante a la del edificio 1 de Cerro Cepero, donde sirve para levantar una obra de opus quadratum, que podemos fechar en la primera mitad del siglo I d.C. (Adroher et alii., 2014, 281). Esto nos permite hipotetizar que estas piezas arquitectónicas fueron el alzado de esa cimentación, aunque no conservemos ninguna huella evidente en la misma que nos permita asegurarlo.

Estos relieves pseudoarquitectónicos a base de pilastras son bastante comunes en la arquitectura funeraria romana del Alto Guadalquivir, como en Castulo (Baena y Beltrán, 2002, no 45, 62, 67, 68, 70 y 80), Iliturgi (Baena y Beltrán, 2002, no 96-100, 102-103 y 107) y Salaria (Baena y Beltrán, 2002, no 151 y 153), con una cronología del siglo I d.C., aunque algunos concretan sus dataciones en época augustea, como los 

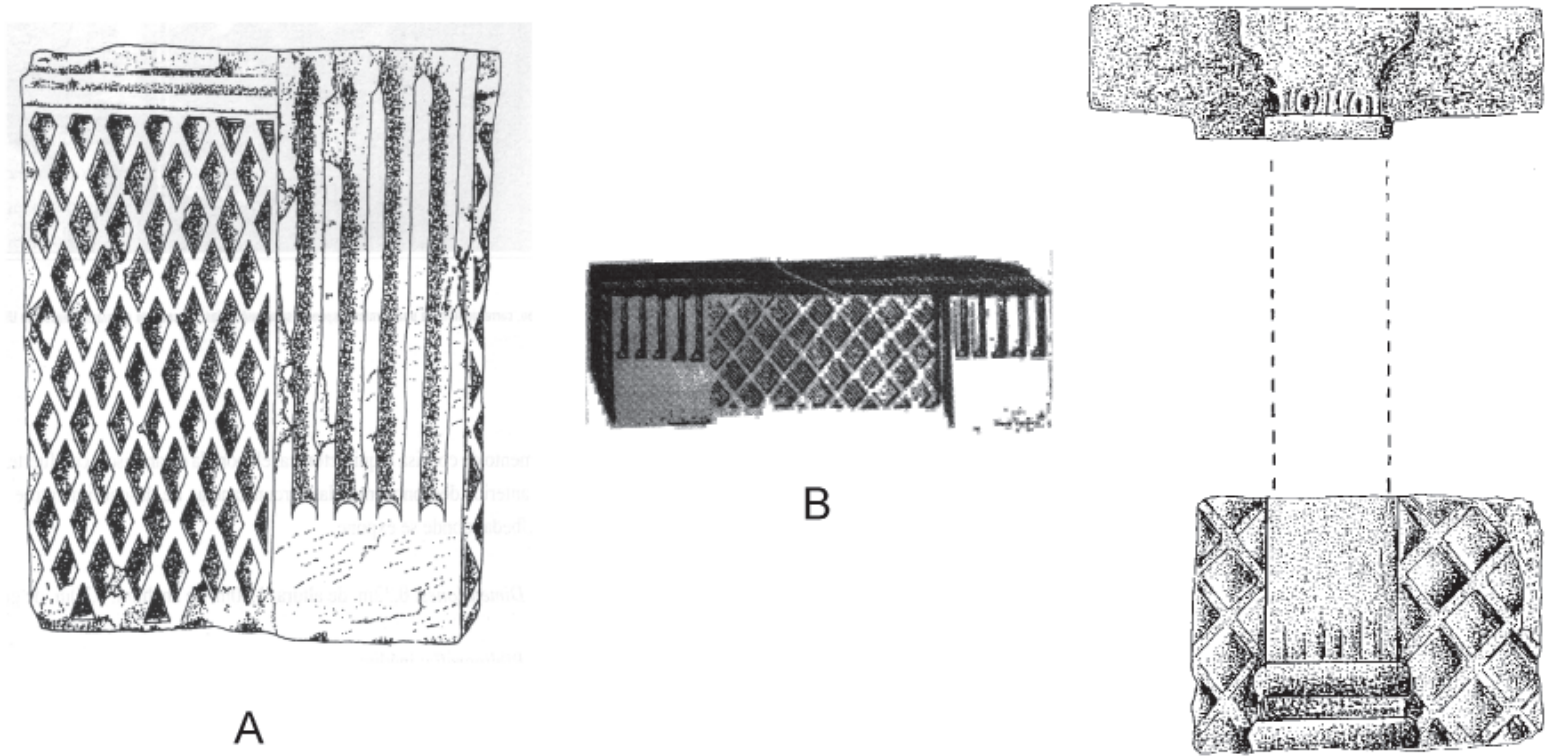

C

A

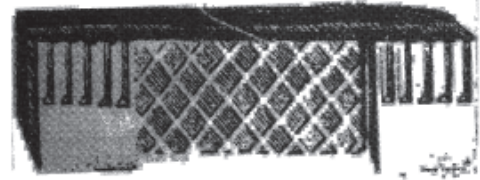

B

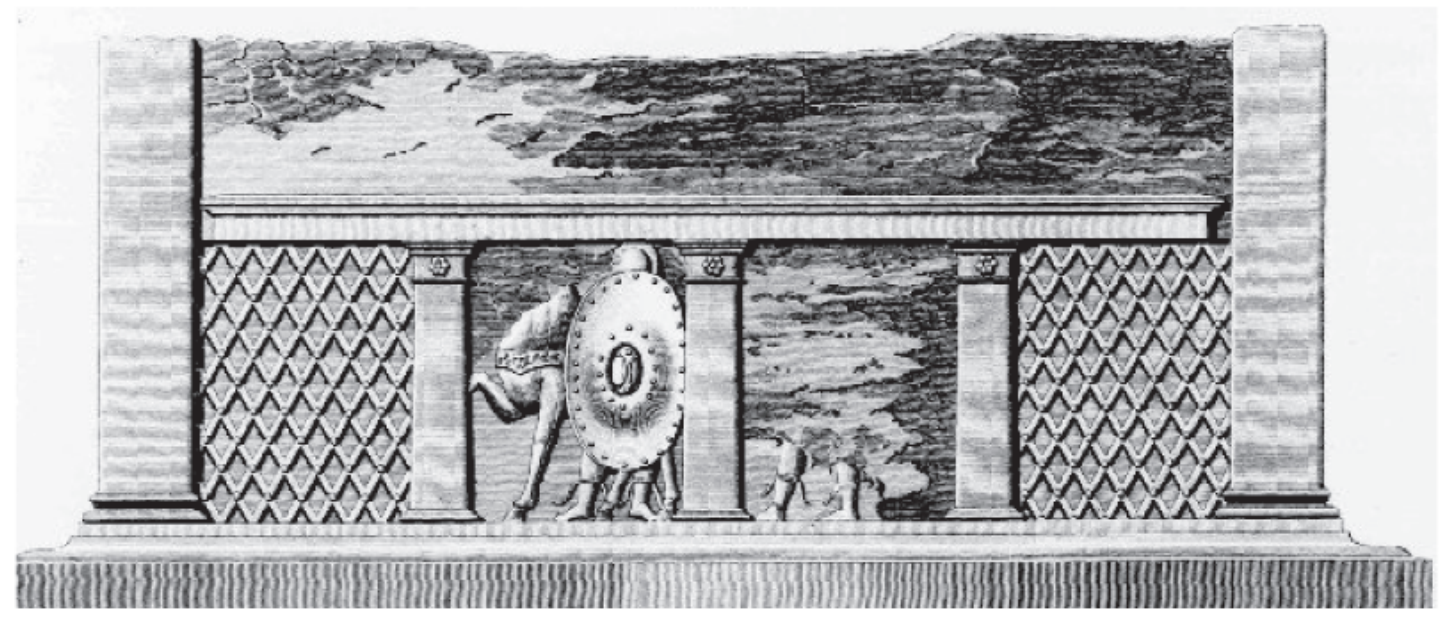

Figura 11. Elementos arquitectónicos de pilastra y celosía. A, Salaria (Beltrán y Baena, 1996, 55); B, Castulo (Beltrán, 2004, 123); C, Ilunum (Abad, 2002, 278); y D, Pompeya (Mazois, 1824, planche XVI, fig. II).

de Salaria, e incluso en el siglo I a.C., como sucede con una pieza de Castulo (Baena y Beltrán, 2002, nº 45)

La decoración de rombos calados que presenta la pieza $\mathrm{B}$ se denomina de valla o celosía es un motivo de origen itálico, como puede observarse en la tumba de Marcus Popidius de la necrópolis de Porta Ercolano de Pompeya, fechada en el último cuarto del siglo I a.C. (Kockel, 1983, 191-194; Campbell, 2015, 182). En Hispania este motivo no es desconocido, así lo encontramos en una pieza de Salaria, asociada al monumento turriforme augusteo de los Staccii documentado en Salaria (Beltrán y Baena, 1996, 54-55), el cual presenta una decoración en su cuerpo inferior consistente en pilastras de cuatro acanaladuras, acompañadas en su extremo inferior de un relieve romboidal semejante al que hemos mencionado para nuestro caso. Otras piezas de factura semejante las encontramos en Castulo, donde F. Pérez Bayer dibujó una pieza similar (Mestre Sanchís et alii, 1998, 206), con falsas pilastras y el mismo dibujo de celosía; y en Ilunum (Abad et alii, 2002, 278; Sarabia, 2004, 561) se conoce una placa de relieve con una pseudopilastra, que viene acompañada de una decoración de celosía y que, también, se asocia a un posible monumento funerario.

\section{MATERIALES ASOCIADOS}

Una tarea fundamental de la intervención realizada en el yacimiento de Cerro del Santuario durante el año 2013, fue la retirada de una parte de las terreras de 

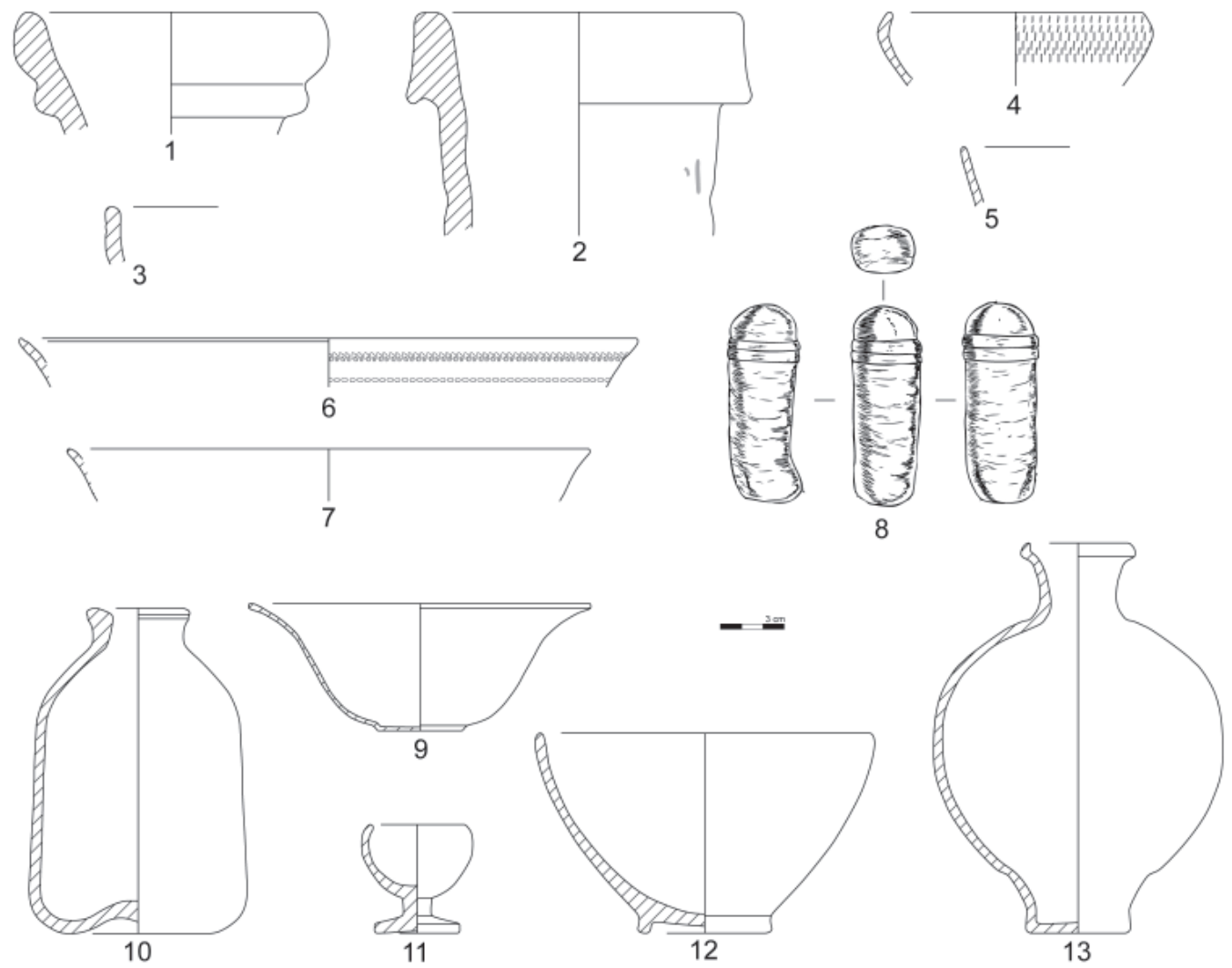

Figura 12: Selección del material cerámico extraído de las terreras y del superficial publicado por F. Presedo y que estaría relacionado con la tumba monumental romana. 1, ánfora Lomba do Canho 67; 2, ánfora Dr. 8, con tituli picti; 3, terra sigillata africana A Hay. 9B; 4-7, terra sigillata hispánica tardía meridional; 8, pieza labrada en mármol; 9, posible terra sigillata hispánica tardía meridional; 10-12, diversas formas de cerámica común romana; y 13, posible jarro o jarra medieval (elaboración propia excepto 8-13, a partir de Presedo, 1982, fig. 205, 206 y 209).

las excavaciones de 1968-1971, que se encontraban y aún se encuentran cubriendo buena parte de las áreas excavadas en aquellas campañas. El desmonte de las mismas se ha realizado cribando en seco la tierra, con el objeto de recuperar cualquier evidencia obviada en dicha intervención arqueológica.

Procedentes de esos trabajos tenemos una serie de materiales cerámicos que, si bien se encuentran completamente descontextualizados, pueden ayudarnos a precisar cronológicamente la época de uso de este edificio funerario y de las posteriores inhumaciones aparecidas en la estancia oriental, ante la total ausencia de una estratigrafía ${ }^{7}$.

Entre ese material, donde predominan absolutamente los elementos relacionables con la época de la necrópolis ibérica, hemos identificado los siguientes

7. Con la que ya nunca podremos contar pues las excavaciones de Presedo arrasaron los posibles contactos estratigráficos de choque con los muros, lo que agrava el hecho de que se trate, como hemos descrito más arriba, de los elementos fundacionales, por tanto estaría por debajo de los niveles de circulación y uso de la misma, a excepción hecha de la estancia occidental, lo que nos permite considerar que se trata de una estancia tipo semisótano. elementos de las fase romana: ánfora Lomba do Canho 67, cuya cronología de difusión es el tercer cuarto del siglo I a.C. (Molina, 2001, 640); ánfora Dr. 8, con titulus pictus en rojo, en el que se solo se reconoce una posible I, y cuya cronología de producción es de época augustea (García y Bernal, 2008, 668); terra sigillata sudgálica, con un único fragmento informe documentado; african red slip ware A Hay. 9B, con cronología del siglo II (Serrano Ramos, 2005, 231); ARSW D, con un único fragmento informe documentado; terra sigillata hispánica tardía meridional formas 1,2 y 3, con una cronología de los siglos IV y V (Orfila, 2008, 543-545); y producciones de torno lento o torneta, en las que ha sido imposible reconocer forma alguna (Fig. 12). Además, existen algunos elementos recogidos por Presedo en superficie, que no parecen responder a la cronología de la necrópolis ibérica.

Este elenco material nos define un arco cronológico entre mediados del siglo I a.C. hasta por lo menos el siglo V d. C., siendo el grupo más numeroso el de la terra sigillata hispánica tardía meridional, el cual podría estar definiendo el momento de la instalación de las inhumaciones en el pórtico del monumento y al exterior del mismo, significando estas la ruina parcial de la construcción y el reaprovechamiento de piezas 
del mismo para estos enterramientos tardíos. Recientemente ha sido documentado en superficie algún elemento de Campaniense A y de vasitos de paredes finas sin engobe, que nos permitirían ampliar la cronología quizás a finales del siglo II a.C.

El problema estriba en canalizar adecuadamente la existencia de estas piezas en una necrópolis ibérica que, por lo que actualmente sabemos, deja de estar en funcionamiento a finales del siglo IV o principios del siglo III a.C. De haber sido utilizada como necrópolis hasta el siglo II a.C. sin duda hubiésemos encontramos más fragmentos de Campaniense $\mathrm{A}$, como sucede en las vecinas necrópolis de El Cigarralejo de Mula o de Coimbra del Barranco Ancho de Jumilla. Por tanto seguimos considerando que estos materiales no nos hablan de un uso funerario de la necrópolis, sino de otro tipo de funcionalidad para la misma, pudiendo tratarse simplemente de frecuentaciones puntuales sin más función que la de paso, o, como parece más probable vista la variedad de material y su continuidad hasta una época tan tardía, una continuidad de uso durante unos siglos después de obliterar la necrópolis, pero manteniendo el carácter simbólico de la misma, que se cristaliza en un momento determinado con la construcción de un nuevo monumento funerario en época romana. Sobre ello volveremos más adelante.

\section{RECONSTRUCCIÓN HIPOTÉTICA DEL MONUMENTO}

Existe un variado repertorio de tipología arquitectónica para los monumentos romanos conocidos de Hispania: torres de varios pisos con aedicula superior; tumbas de columna; tumbas de altar; con forma de meta; con forma de túmulo; recintos; templiformes; y criptas subterráneas (Hesberg, 1992), lo que nos complica notablemente la labor de nuestro proceso reconstructivo.

Podemos decir, no obstante, que, en principio, la planta del edificio parece sugerir que nos encontramos ante un monumento turriforme, puesto que ésta no encaja con el modelo de monumento templiforme, en el que es necesario una gran losa de cimentación para levantar el podium como, por ejemplo, puede verse en San Nicolás, Valencia (Arnau et alii, 2003). Dentro de los monumentos turriformes el paralelo más evidente es el monumento funerario $\mathrm{n}^{\circ} 496$ de Baelo Claudia (Paris et alii, 1923, fig. 43-44), el cual se compone de una base en forma de cubo en altura y una pirámide como coronación, al que se adosan dos muros paralelos sin alzado aparente, y que se datan en época de Adriano (Hesberg, 1992, 166) (Fig. 13). Estos monumentos funerarios no son infrecuentes en zonas próximas, pues contamos con Torre Ciega de Cartagena, datada en el siglo I a.C. (Abad, 1989) y el Mausoleo de Abla, del siglo II d.C. (Martínez, 1990); existen igualmente algunos casos de tumbas en forma de altar con pulvinos en Vélez Rubio y en Salaria (Beltrán, 2004, 124 y 126), u otros más similares como el monumento del Campo de la Verdad en Córdoba (Vaquerizo, 2001, 148-149).

De este modo apostamos por un espacio abierto, a modo de pórtico, que diera acceso a un segundo espacio, quizás el central del monumento, y que interpretamos como un ámbito turriforme. La consideración de espacio abierto para la estancia más al Este nace del argumento utilizado anteriormente (vs. supra) del hecho de que no existió en ningún momento un muro de cierre oriental de dicha estancia; aunque debemos reconocer que la anchura de los muros, en torno al metro, debería hacernos sospechar de algún elemento de peso, quizás a modo de cubierta, tal vez un arcosolio, en cuyo caso la cámara del fondo sería un espacio privilegiado, y, por supuesto, dado el caso del nivel de suelo, por debajo de la primera estancia. Sin embargo, existiría una alternativa, y es que el espesor de los muros se relacionara con un espacio para la construcción de hornacinas o loculi donde depositar urnas cinerarias, en cuyo caso este espacio debería estar igualmente cubierto. No podemos resolver el problema de este espacio que, en todo caso, en un momento más tardío cuando parte del monumento está arruinado, es utilizado como espacio de enterramiento, como demuestran los restos de dos inhumados que el mismo Presedo localizó durante las excavaciones.

No obstante, vistos los elementos arquitectónicos anteriormente analizados, es más que probable que nos encontremos con un monumento funerario turriforme, y la única estancia que puede responder arquitectónicamente a ello, es la más pequeña. De esta forma podríamos pensar en un cuerpo turriforme propiamente dicho, mientras que la habitación mayor, al no tener una estructura de cierre a modo de puerta, sino estar completamente abierta parece corresponderse mejor a un acceso en antas; no sabemos muy bien cuál sería la altura del nivel de circulación, pero teniendo en cuenta la existencia de una tumba en el acceso y que actualmente descansaría directamente sobre el nivel geológico, hay que considerar una altura que en ningún caso sería inferior a los $50 \mathrm{~cm}$, lo que provoca que estemos ya a la altura de los muros conservados actualmente. Este hecho es importante porque determinará el sistema de acceso a la cámara funeraria, la cual, sin duda, se encuentra por debajo de este nivel de circulación, ya que directamente sobre el nivel geológico y en las dos esquinas más occidentales, como ya se adelantó anteriormente, aún se conservan dos placas de latericia que deben indicar el nivel de uso de dicha cámara.

Dicho acceso solamente se puede realizar a través de unas escaleras, aunque no sabemos cómo pueden haberse resuelto arquitectónicamente ya que el muro que separa las dos estancias no muestra señal alguna que aclare este extremo. Es muy probable que existieran escaleras desde el acceso, para señalar la diferencia simbólica de ambos espacios, al mismo tiempo que al levantarse respecto al suelo de la estancia primera evitaría que el agua de lluvia que cayera en ella pudiera penetrar en la cámara funeraria. Una vez salvado 


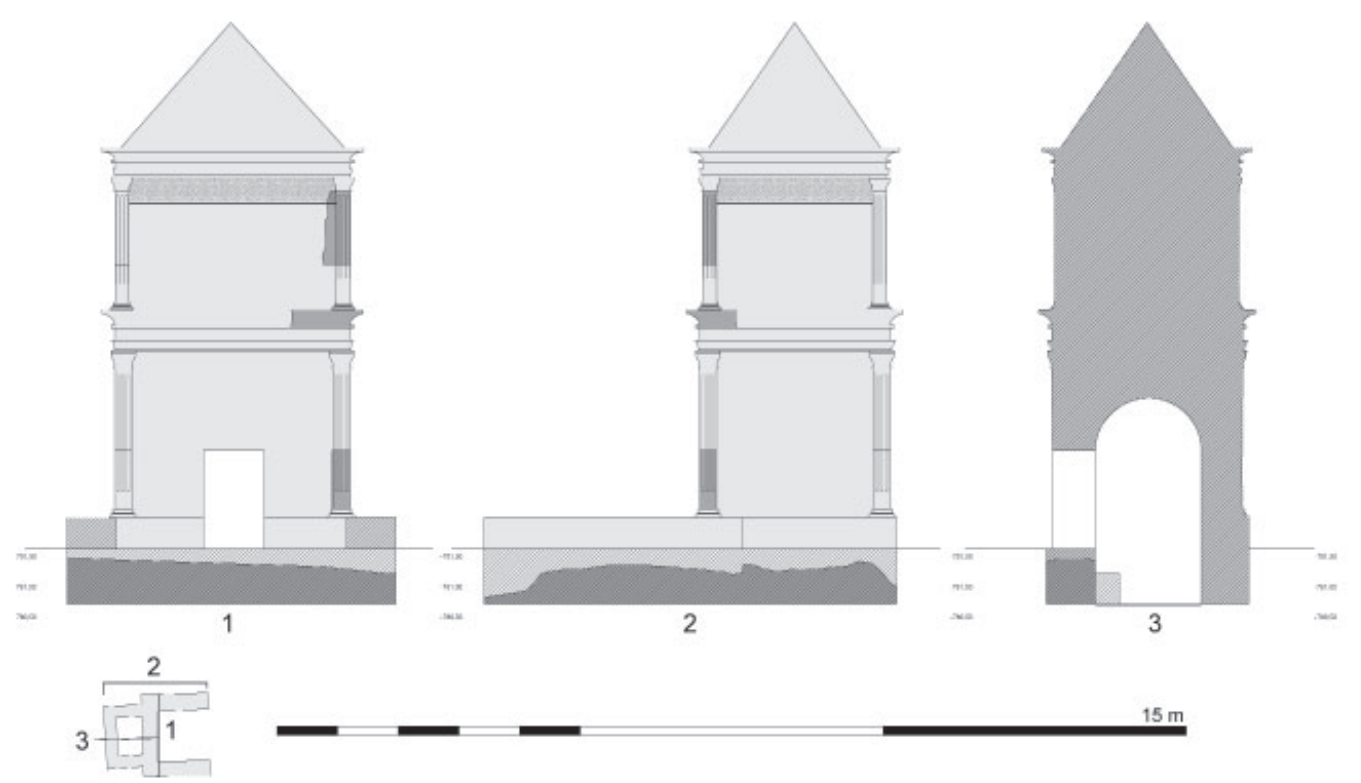

Figura 13: Propuesta ideal de alzado y sección del monumento funerario romano de Cerro del Santuario (elaboración propia).

este escollo existe la posibilidad de que conste de una escalera de descenso, pero insistimos en que hasta el momento no hemos podido detectar ningún elemento que nos confirme o refute dicha propuesta; en principio, y teniendo en cuenta la superficie que ocupa la cámara funeraria no parece que en el caso de existir hacia el interior, las escaleras fueran muy altas, pues apenas hay espacio desde el vano de acceso hacia la pared más occidental de dicha cámara para desarrollar un paso normal con una huella y contrahuella más o menos salvable y cómoda. No podemos saber la altura de la contrahuella, pero parece bastante lógico considerar que la huella debiera medir aproximadamente un pie $(0,296 \mathrm{~m})$, por lo que, teniendo en cuenta la profundidad de la estancia $(1,65 \mathrm{~m})$ apenas cabrían cinco escalones para llegar a la pared del fondo, sobrando sólo diez centímetros de descansillo a la altura del nivel de circulación. De esta forma la cámara quedaría estructuralmente dividida en dos subestancias separadas estructuralmente por la escalera de acceso. Una alternativa sería considerar una puerta en lateral, pegada al muro de separación de las dos estancias. De esta manera si pensamos que el acceso es axial respecto al eje de la estructura funeraria la escalera solamente podría contar con cuatro peldaños como máximo; sin embargo, existiría la posibilidad de que no fuera axial, sino lateral, por lo que entonces podríamos contar con ocho escalones sobrando solamente diez centímetros de rellano. Incluso existiría una opción más, y es que el acceso no estuviera estructurado en materiales nobles como piedra franca, sino que se hubiese construido en materiales perecederos, por ejemplo en madera $\mathrm{y}$, en consecuencia, no se hubiese conservado.

En puridad no podemos inclinarnos por ninguna de estas opciones, si bien es cierto que hay una que parece poco probable a juzgar tanto por los paralelos como por la propia estructura ideológica y simbólica que para el mundo romano supone el concepto de simetría; y en consecuencia no creemos que la puerta no fuese axial respecto al eje del complejo estructural. El resto de las opciones quedan apuntadas a la espera de futuras investigaciones.

La existencia de bancos corridos en las dos alae de las antas parece probable pero no hay elementos estructurales que así nos lo haga saber, quizás a excepción de la anchura de los muros, que pueden alcanzar el metro, lo que parece poco necesario para unos muros que no tienen que soportar peso estructural (es decir, techo, como efectivamente pensamos). De hecho estos dos muros laterales son los más anchos de todo el complejo, y dada la estructura el acceso al mismo parece muy poco probable que estén cubiertos, de modo que quizás su anchura se deba precisamente a la existencia de dichos bancos corridos. Este tipo de elementos se encuentran en edificios funerarios como el Mausoleo de Abla, en Almería.

Centrándonos en la estructura propiamente dicha consideramos la posibilidad de la existencia de varios cuerpos rematados por un pináculo piramidal, siguiendo los modelos propios de los monumentos turriformes que parecen inspirarse en estructuras de origen norteafricano (Prados, 2008).

Podemos asegurar al menos la existencia de dos cuerpos, lo que vendría evidenciado por el hecho de que las dos pilastras recuperadas hasta el momento presentan unas dimensiones diferentes en lo que a la anchura se refiere, por lo que no deben formar parte del mismo registro decorativo. Podría darse el caso de la existencia de un primer cuerpo de cantería sin decoración arquitectónica, sobre el que se elevarían los otros dos cada uno con su ritmo decorativo, pero parece poco probable dadas las dimensiones de la estancia occidental, que no permiten considerar un edificio de una altura tan elevada. La composición decorativa 
debió ser similar en los dos cuerpos, con sillares esquineros a modo de pilar de caliza, con acanaladuras verticales, del tipo de la figura 9a; es probable que las placas de decoración arquitectónicas existentes en el Museo de Baza (Fig. 9b) culminarán la parte superior del tercer cuerpo el cual estaría separado del remate piramidal por la cornisa que Presedo localizó y asoció a la tumba 123. Hemos rematado con el orden corintio ya que a todas luces fue el más extendido en general en la Bética romana.

\section{6. ¿UN MONUMENTO FUNERARIO DE UNA FA- MILIA DE ORIGEN LATINO?}

Una vez presentada nuestra propuesta, debemos preguntarnos por el origen de la familia que pudo ordenar la construcción de este monumento funerario, para su mayor gloria y renombre. Aunque antes de establecer nuestra hipótesis sobre esta cuestión, nos gustaría subrayar varias cuestiones previas que nos parecen interesantes para el relato que proponemos.

Así, en primer lugar, señalemos que la cronología de uso más probable de la necrópolis ibérica del cerro del Santuario de manera continuada iría desde el último tercio del siglo $\mathrm{V}$ a. C -según la cronología propuesta para la tumba 183 (Caballero et alii, 2013)hasta el siglo III a. C., por tanto, antes de la llegada de los romanos. Pero la presunta monumentalidad hacia el exterior de algunas de las tumbas excavadas por $\mathrm{F}$. Presedo ${ }^{8}$ y la mencionada tumba 183 hallada en 2013, haría bastante probable que el recuerdo y el prestigio de esta importante necrópolis ibérica llegara hasta la época imperial romana.

Respecto a la gens documentada en la zona de Bas$t i$ que pudiera tener relación con la tumba monumental que estamos tratando, por el momento, sólo contamos con una opción según las inscripciones halladas. Se trata del nomen Atellius, de origen itálico y documentados en la ciudad de Carthago Nova a partir del año 88 a.C., por los epígrafes aparecidos en un lingote de plomo, en diversas inscripciones y en algunas de las primeras monedas emitidas en dicha ciudad. Tras llegar a Carthago Nova desde Herculaneum (Herculano, Campania), ya que la tribu a la que pertenecerían -la Menenia - se localiza originariamente en esta ciudad del sur de la Península Itálica, se harían con el control de algunas explotaciones mineras cercanas a esta ciudad hispana (Llorens Forcada, 1994, 44; Abascal Palazón y Ramallo Asensio, 1997, 131; Díaz Ariño, 2008, 128; Barreda Pascual, 1998, 162 y ss.).

Desde sus inicios en Carthago Nova, se extendieron a otras áreas de Murcia y por los altiplanos de Granada, seguramente vinculados a las diversas explotaciones mineras que tanto abundan en esta zona.

8. En concreto las tumbas $9,67,94$ y 130 presentaban restos de túmulos de adobes (Presedo, 1982).
Así, en el oppidum de Tutugi (Cerro del Real, Galera) se halló una inscripción en honor del emperador Marco Aurelio (161-180), costeada por el duunvir del ordo de los decuriones municipales Publius Atellius ¿Chanus?9. En Acci (Guadix), contamos con otra inscripción, en este caso funeraria, donde aparecen los nombres de tres miembros pertenecientes a esta gens: el padre Publio Atellius Paulino y los dos hijos Procula Atellius y Paulus Attellius ${ }^{10}$. Finalmente, en las cercanías de Basti, se localizó una inscripción funeraria bastante incompleta dedicada a Quintus Atellius Iucundus ${ }^{11}$; además, debemos mencionar también los fragmentos de una inscripción que hace referencia a una tal $\mathrm{Felicia}^{12}$, que habría sido esclava de la rama familiar de los Atellius radicada en Basti.

Estas últimas son las únicas referencias epigráficas conservadas hasta la fecha en el área de Basti relacionadas con una familia de origen latino, que por su riqueza conseguida por la concesión de las explotaciones mineras bien pudiera haber ordenado construir el monumento funerario que presentamos en este trabajo.

\section{CONCLUSIONES}

La constatación de una estructura funeraria romana sobre el lugar de una antigua necrópolis ibérica resulta doblemente interesante, en primer lugar por la continuidad de uso de un espacio mortuorio y en segundo lugar porque esta continuidad en realidad presenta un claro hiatus de varias generaciones entre los últimos momentos de la ocupación ibérica y los primeros momentos de la romana.

Hay un serio problema con la cronología de la construcción de este edificio; si bien hemos podido asumir que la necrópolis ibérica pudo haberse convertido en un espacio de culto, sin uso funerario, desde el siglo II a.C., la continuidad presencial de materiales hasta los siglos VI-VII d.C. solo nos permite concebir que este espacio sigue siendo considerado sagrado durante mucho tiempo. Incluso es posible que el topónimo con que actualmente se conoce a esta zona (Los Santuarios) y que da nombre al yacimiento (con anterioridad a las excavaciones de Presedo) indique una pervivencia en el uso sagrado de este espacio.

Los monumentos funerarios turriformes tienen una gran presencia en época ibérica, muy probablemente bajo los efectos de comunidades semitas, que con la presencia bárquida se pudieron potenciar, como sucede en el Norte de África (Prados, 2008). Las cornisas en gola pueden seguir en uso hasta época republicana como se apuntan en las recientes excavaciones de la necrópolis de Baelo Claudia (Prados y Jiménez,

\footnotetext{
9. $A E ., 1983,609=A E ., 1984,598 ; C I L A, 4,204$

10. $C I L$, II, 3003=CIL, II, 5834=ILPGr, 81; CILA, 4, 213

11. CIL, II, 3405=ILPGr, 21; CILA, 4: 199

12. CIL, II, 3405=IBPGR, 21; CILA, 4: 199.
} 
2015); por otro lado podemos asegurar que las inhumaciones más tardías pudieron tener lugar en torno al siglo VIII d.C. ${ }^{13}$, ya que entre el ajuar funerario localizado por el propio Presedo aparecen vasos de vidrio, lo que no se prodiga a partir del siglo IV-V d.C. Y en ese momento, parte de la edificación ya ha caído, reutilizándose parte de la arquitectura decorativa como elementos de construcción de las nuevas tumbas. Por tanto nos podemos mover, en principio, entre los siglos II a.C. y V d.C. Solamente los elementos decorativos y algunas reflexiones más acerca del material cerámico recuperado en la limpieza de las terreras nos pueden cerrar algo más la cronología. Sin duda, durante el momento de la construcción del edificio debió producirse un incremento en los niveles de circulación y uso del cerro, por lo que descartamos el siglo II a.C. por la escasez de materiales asociados a esta época. Sin embargo, están mejor representadas las cerámicas del siglo I a.C., por lo que no sería desdeñable proponer, inicialmente la construcción de este monumento quizás a los últimos momentos de la República o los primeros del Imperio. Por otro lado, la presencia de las decoraciones en rombo nos remiten a época augustea cuando habría que datar el paralelo de Salaria (Beltrán y Baena, 1996, 37); así pues, entre los diversos elementos consideramos que este monumento debió haberse construido entre finales del siglo I a.C. y la primera mitad del siglo I d.C.

Ante la cronología tan amplia en que se desarrolla el uso de este espacio de nuevo con carácter funerario, somos conscientes de la existencia de un elementos simbólico en la reutilización de una necrópolis indígena que permaneció en desuso durante poco más de dos siglos, y que vuelve a activarse cuando, en principio, no existiría conexión con los usuarios primigenios de la misma.

Es probable que quedase la memoria de este espacio como santuario, recuerdo de los ancestros que fueron enterrados en él. En algún momento determinado se pudo recuperar algún rito en memoria de ellos, hasta que ese rito se sistematizó y alguien decidió sacralizar de nuevo este espacio pero con una simbología claramente romana, momento de la construcción del monumento; quizás sea más plausible considerar que el monumento turriforme es una consecuencia de la

13. De hecho no sería buena idea dejar de lado la descripción de la posición de uno de los individuos localizados en la tumba de inhumación al exterior del monumento, cuyo cadáver, según las palabras del propio Presedo estaba «...recostado sobre el lado derecho con la cabeza hacia el W y los huesos con cierto desorden, aunque conservando la postura del enterramiento.» (Presedo, 1982, 258). Parece que en realidad se trata de un enterramiento islámico a juzgar por la posición en decúbito lateral derecho y a la carencia de ajuar funerario; es posible pues que se haya mantenido la utilización del espacio de Cerro del Santuario durante algo más de mil quinientos años, siempre con un carácter sagrado de características funerarias. sacralización del espacio más que al contrario, que el monumento se construya ex nihilo, y que se convierta en causa única de dicha sacralización. Es bastante más coherente considerar que se sistematiza un espacio sagrado apropiándose de él con el objetivo de perpetuar la memoria y justificar la pertenencia a un status social amparado por los ancestros. La recuperación de esta memoria de la muerte es un fenómeno que, aunque no suficientemente estudiado, si ha sido documentado con cierta frecuencia (García Sanjuán, 2005).

En este sentido no debemos olvidar la ubicación del monumento, puesto que parece tener una importancia fundamental en el paisaje del espacio periurbano de Basti. Se sitúa en el centro de la unidad geomorfológica donde se asienta la necrópolis ibérica, lo que además lo emplaza en el punto topográfico más elevado de la misma, obviamente respecto al perfil original del cerro, ya que en la actualidad éste se encuentra muy alterado por la repartición de las lomas que fueron configuradas por las terreras que se iban acumulando durante la excavación de las diversas tumbas. No cabe duda que se erigió buscando una amplia visibilidad sobre el entorno, un impacto desde el centro del poder sito en el oppidum ya romano y a su vez un control sobre todo lo antecedente en la necrópolis, que protege al aristócrata a la vez que justifica su linaje.

Nos encontraríamos ante un interesante ejemplo de perduración de los espacios sagrados, que se resacralizarían sistemáticamente, $\mathrm{y}$, en este caso, serviría al final de su existencia como hito en torno al cual crear una pequeña necrópolis que pudo subsistir entre la Antigüedad Tardía y la Alta Edad Media....quizás esto justificaría que hasta la actualidad haya llegado el topónimo, ya cristianizado, de Cerro del Santuario.

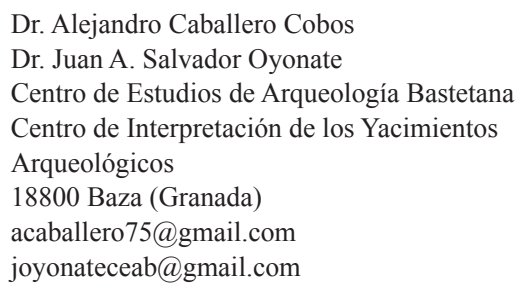

Prof. Dr. Andrés María Adroher Auroux Departamento de Prehistoria y Arqueología Universidad de Granada Campus Universitario de Cartuja 18071 Granada aadroher@ugr.es

\section{BIBLIOGRAFÍA}

ABAD CASAL, L., 1989: «La Torre Ciega de Cartagena (Murcia)», Homenaje al prof. Blanco Freijeiro, 243263, Madrid.

ABAD CASAL, L., ABASCAL PALAZÓN, J.M. y SANZ GAMO, R., 2002: «Monumentos funerarios romanos de época romana en la provincia de Albacete», en II Congreso de Historia de Albacete, I, Arqueología y Prehistoria, 271-282. 
ABASCAL PALAZÓN, J.M. y RAMALLO ASENSIO, S.F., 1997: La ciudad de Carthago Nova: la documentación epigráfica, Murcia.

ADROHER AUROUX, A.M ${ }^{\mathrm{a}}$, CABALLERO COBOS, A y SALVADOR OYONATE, J.A., 2014: «Una historia de las investigaciones en Basti (Baza, Granada)», Cuadernos de Prehistoria y Arqueología de la Universidad de Granada, 23, 265-291.

ALMAGRO GORBEA, M., 1983: «Pozo Moro. El monumento orientalizante, su contexto cultural y sus paralelos en la arquitectura funeraria ibérica», Madrider Mitteilungen, 24, 177-293.

ARNAU DAVÓ, B., GARCÍA VILLANUEVA, I., RUIZ VAL, E. y SERRANO MARCOS, Ma I., 2003: «El monumento funerario templiforme de la plaza de San Nicolás, Valencia, y su contexto arqueológico», Saguntum: Papeles del Laboratorio de Arqueología de Valencia, 35, 177-195.

BARREDA PASCUAL, A., 1998: Gentes itálicas en Hispania Citerior (218-14 d. C.). Los casos de Tarraco, Carthago Nova y Valentia, Barcelona, Tesis Doctoral.

BAENA DEL ALCÁZAR, L. y BELTRÁN FORTES, J., 2002: Las esculturas romanas de la provincia de Jaén, C.S.I.R. I, 2, 2002, Murcia.

BELTRÁN FORTES, J. y BAENA DEL ALCÁZAR, L., 1996: Arquitectura funeraria romana de la colonia $\mathrm{Sa}$ laria. Ensayo de sistematización de los monumentos funerarios altoimperiales del alto Guadalquivir, Sevilla.

BELTRÁN FORTES, J., 2004: «Monumenta sepulcrales en forma de altar con pulvinos de los territorios hispanorromanos: revisión de materiales y estado de la cuestión», Archivo Español de Arqueología, 77, 101-141.

CABALLERO COBOS, A., ADROHER AUROUX, A.M ${ }^{\mathrm{a}}$, RAMÍREZ AYAS, M., SALVADOR OYONATE, J.A. y SÁNCHEZ QUIRANTE, L. 2013: «Nueva tumba, de inhumación infantil, en la necrópolis ibérica de Cerro del Santuario (Baza, Granada): Resultados Preliminares», Revista Bastetania, 1/12,115-131.

CAMPBELL, V.L., 2015: The tombs of Pompeii: organization, space and society, Taylor \& Francis, New York.

DÍAZ ARIÑO, B., 2008: Epigrafía latina republicana de Hispania (ELRH), Col·lecció Instrumenta 26, Barcelona.

GARCÍA VARGAS, E. y BERNAL CASASOLA, D., 2008: "Ánforas de la Bética», en D. Bernal Casasola y A. Ribera i Lacomba (eds.), Cerámicas hispanorromanas. Un estado de la cuestión, 661-688, Cádiz.

KOCKEL, V., 1983: Die grabbauten vor dem Herkulaner Tor in Pompeji, Mainz am Rhein.

HESBERG, von H., 1992: «Römische Grabbautem in den hispanische provinzen», en W. Trilmich, T.H. Hauschild, M. Blech, H.G. Niemeyer, A. Nunnerich-Asmus y U. Kreilinger, Denkmaler der Romerzeit, 159-182.
IZQUIERDO PERAILE, I., 2000: Monumentos funerarios ibéricos: los pilares-estela, Trabajos Varios del SIP 98, Valencia.

JIMÉNEZ SALVADOR, J.L., 1992: «Monumento funerario romano de Sagunto», Estudios de arqueología ibérica y romana. Homenaje a Enrique Plá Ballester, 539-554, Valencia.

LLORENS FORCADA, Ma M., 1994: La ciudad romana de Carthago Nova: las emisiones romanas, Murcia.

MARTÍNEZ GARCÍA, 1990. Julián Martínez García: «El mausoleo altoimperial de Abla (Abla, Almería)», en Anuario Arqueológico Andalucía/1987/III, (1990), 7-17.

MAZOIS, F., 1824: Les ruines de Pompéi, vol. I, Pierre et Ambroise Firmin Didot, París.

MESTRE SANCHIS, A., PÉREZ GARCÍA, P. y CATALÁ SANZ, J.A., 1998: Francisco Pérez Bayer: viajes literarios, Valencia.

MOLINA VIDAL, J., 2001: «Las primeras exportaciones béticas en el Mediterráneo Occidental», en Actas del Congreso Internacional Ex Baetica Amphorae, 637645, Écija.

PARIS, P., BONSOR, G.E., LAUMONIER, A., MERGELINA, C. y RICARD, R., 1923: Fouilles de Belo (Bolonia, province de Cadix, 1917-1921), Vol. 2, Bordeaux.

ORFILA PONS, M., 2008: «La vajilla Terra Sigillata Hispánica Tardía Meridional», en D. Bernal Casasola y A. Ribera i Lacomba (eds.), Cerámicas hispanorromanas. Un estado de la cuestión, 541-552.

PRADOS MARTÍNEZ, F., 2008: Arquitectura púnica. Los monumentos funerarios, Anejos de Archivo Español de Arqueología 44, Madrid.

PRESEDO VELO, F., 1982: La necrópolis de Baza, Excavaciones Arqueológicas en España 119, Madrid.

RUIZ-ALCALDE, D., CHARQUERO BALLESTER, A.M., 2014: «El monumento funerario romano de la Torre de Sant Josep de Villajoyosa (Alicante). Nuevos datos y propuesta de restitución», Lucentum, 33, 151-182.

SARABIA BAUTISTA, J., 2004: «La decoración arquitectónica en la ciudad romana de Ilunum (El Tolmo de Minateda, Hellín, Albacete)», en S. Ramallo (ed.), La decoración arquitectónica en las ciudades romanas de Occidente, 559-564, Murcia.

SERRANO RAMOS, E., 2005: «Cerámicas africanas», en M. Roca Roumens y M ${ }^{\mathrm{a}}$ I. Fernández García (coords.), Introducción al estudio de la cerámica romana. Una breve guía de referencia, Monográfico de CVDAS, 225304, Andújar.

VAQUERIZO GIL, D., 2001: «Formas arquitectónicas funerarias de carácter monumental en Colonia Patricia Corduba», Archivo Español de Arqueología, 74, 131-160. 